\title{
Epidemiological Investigation of Patients with Advanced-age Femoral Neck Fracture and Evaluation of Surgical Results
}

\author{
(D) Ömer Özel \\ Başkent University Faculty of Medicine, Department of Orthopaedics and Traumatology, Istanbul, Turkey
}

\section{Abstract}

Objective: The investigation of the epidemiological status of patients who underwent partial hip replacement is necessary by evaluating their postoperative status based on the hip score so as to examine the effect of additional diseases on postoperative recovery and survival.

Methods: A total of 99 patients who underwent partial hip replacement between September 2013 and 2017 for femoral neck fracture were included in the study. Preoperative diabetes status and presence of additional diseases were examined. Harris scoring form was filled up by all patients. Osteoporosis treatment and additional fracture were evaluated at the final follow-up examination.

Results: The mean age of the 99 study subjects [36 (36.4\%) men, 63 (63.6\%) women] of all, 18 (18.2\%) patients had diabetes and 12 (12.1\%) had postoperative fractures. In addition, 17 (17.2\%) patients received regular osteoporosis treatment and 4 patients (4.1\%) were diagnosed with malignancy from the femoral head. Additional diseases were recorded in 21 (21.2\%) patients. The mean Hip Harris score of the patients was $53.62 \pm 12.71$. A total of 22 (22.2\%) patients died during the follow-up. Exitus was significantly lower in patients with high postoperative Harris score $(p<0.001)$. No differences were noted between the alive and dead patients with respect to the factors of age, sex, diabetes, additional fracture, and other diseases. Exitus was significantly lower in patients receiving regular osteoporosis treatment $(p=0.001)$. No difference was noted in terms of living additional fracture, age, and Harris score. The sex of the patient had no significant effect on the Harris score.

Conclusion: The most important factors affecting survival in patients who were followed up for femoral neck fracture included the high postoperative Harris score, regular osteoporosis treatment received by the patients, and additional fracture experiences.

Keywords: Collum femoris fracture, partial hip replacement, osteoporosis, epidemiology

\section{INTRODUCTION}

Femoral neck fractures are commonly encountered injuries in the orthopedic practices and can result in significant morbidity and mortality among elderly. Osteoporosis and neurological disorders are one of the most important risk factors that affect not only women but also men of advanced ages. Femoral fractures represent an increasing financial burden within the total healthcare system and the society considering the deterioration of mobility, limitation of the quality of life, and reduction in the life expectancy $(1,2)$. Hip fractures can be categorized as intercapsuler femoral neck fractures and trochanteric fractures.
According to the American Academy of Orthopedic Surgeons' Evidence-Based Guideline on the management of displaced femoral neck fractures in elderly, either total or partial hip replacement surgery is preferred in relation with the activity of patients, the quality of the bone, and presence of comorbidities (3). Partial hip replacement surgery is the most preferred surgical option for elderly with sustained femoral neck fracture in our country. The Harris Hip score is a clinician-based outcome measure for the postsurgical evaluation of the activity levels of the patients (4). Age and comorbidities are the factors that have an important impact on the Harris Hip scores and life expectancy

Phone: +90 5054771236 E-mail: omerozel79@hotmail.com ORCID ID: orcid.org/0000-0002-6859-017X

Cite this article as: Özel Ö. Epidemiological Investigation of Patients with Advanced-age Femoral Neck Fracture and Evaluation of Surgical Results. Eur Arch Med Res 2020;36(4):263-6

- Copyright 2020 by the University of Health Sciences Turkey, Prof. Dr. Cemil Taş̧̧ığlu City Hospital

European Archives of Medical Research published by Galenos Publishing House. 
(5). Further epidemiological investigations are required to evaluate the effects of comorbidities, life quality, and life expectancy for patients who undergo partial hip replacement surgery in our country. The purpose of this study was to evaluate the patients who underwent partial hip replacement surgery for femoral neck fracture by means of their Harris Hip score in order to assess the postoperative conditions as well as the effects of the presence of comorbidities and postoperative life expectancy on the well-being of the patients.

\section{METHODS}

We evaluated the patients operated for femoral neck replacement during September 2013-2017 by retrospective analysis. A total of 127 patients were included in this study. The study exclusion criteria were the impossibility to reach the patient's relatives, the lack of postoperative follow-up in the $6^{\text {th }}$ month, the lack of the recording of Harris Hip score form, and postoperative wound infection and advanced heart failure. In addition, 99 patients who met the inclusion criteria were included in the study.

The study design was reviewed and approved by the Baskent University Faculty of Medicine Human Research Ethics Committee (K/A 19-408). All investigations conformed to the ethical principles of research, and informed consent for their participation in this study was obtained from all patients.

All patients were approached by means of modified Gibson incision posterolaterally; the outer rotator muscles were reflected and a T-shaped incision was made in the hip capsule to reveal the underlying deep anatomical structures. The physical therapy program was outlined as to when the patient could sit, start the motion of the operated hip, and begin ambulation immediately on the day after the surgery. Postoperative followup was performed at 1.5-2 months of the surgery. The Harris Hip score was recorded at postoperative $6^{\text {th }}$ month. Osteoporosis therapy was initiated for patients with the appropriate general medical conditions. The quality of life, the presence of additional fractures, and the stages of osteoporosis treatment were evaluated by means of recalling the patients or the patients' relatives. The patients who received $\geq 2$ years of osteoporosis treatment were accepted as those who were receiving regular osteoporosis treatment. All the patients were diagnosed for the presence of diabetes pre-surgically and chronic renal disease and neurological disease both pre- and post-surgically.

\section{Statistical Analysis}

Data were analyzed using the SPSS statistical software (version 17.0; SPSS Inc., SPSS Inc., Chicago, IL, USA). The variations showing parametric distribution were described as mean + standard deviation, while the non-parametric distribution was described as median (minimum-maximum). We decided that the data should be parametric or non-parametric by looking at the Kolmogorov-Smirnov or Shapiro-Wilk tests and the histogram distributions. Chi-square test or Fisher Exact test statistic were used to compare the categorical variables. Quantitative variables were compared using t-test, while chi-square test was applied to compare the qualitative variables. The significance threshold was set at 0.05 .

\section{RESULTS}

A total of 99 patients were enrolled in this study. The mean age of the patients [36 men (36\%), 63 women (63\%)] was $81.23+8.34$ years. The mean postoperative follow-up period was 41 (8-75) months. A total of 18 patients (18.2\%) had diabetes and 12 (12.1\%) developed additional fractures later. Only 17 patients (17.2\%) received regular osteoporosis therapy. According to the pathology reports, 4 patients (4.1\%) were diagnosed with malignancy and 21 patients (21.2\%) with neurological diseases and chronic renal diseases. The mean Harris Hip score was $53.62+12.71$. A total of 22 patients $(22.2 \%)$ in this study were exitus during the follow-up period (Table 1).

The postoperative Harris Hip score was significantly greater in alive patients than in exitus patients $(p<0.001)$. No significant difference was noted between the alive and exitus groups for the factors of age, gender, diabetes, additional fracture, and comorbidities ( $p=0.43, p=0.34, p=0.72, p=0.55$, respectively). All patients who received regular osteoporosis treatment were found to be alive; thus, when compared to exitus patients, osteoporosis treatment showed a significantly better effect on the life expectancy (Table 2). There was no statistically significant difference between the factors of gender and presence of diabetes when additional fractures were concerned ( $p=0.051, p=0.45$, respectively). Two patients receiving regular osteoporosis treatment had additional fractures, which was not statistically significant ( $p=0.051, p=0.45$ ). In addition, no statistically significant difference was detected among the factors of age, postoperative Harris Hip score, and comorbidities by means of additional fractures $(p=0.90, p=0.60, p=0.71$, respectively) (Table 3). No statistically significant difference was noted between the gender and Harris Hip score (Table 2).

\section{DISCUSSION}

Most studies on the determinants of osteoporosis-related fractures have been dedicated to hip fractures in aging population 


\begin{tabular}{|l|l|l|l|l|l|l|l|l|l|}
\hline \multicolumn{2}{|l|}{ Table 1. The epidemiological evaluation of the study population } \\
\hline $\mathbf{n}$ & Age & M/F & $\begin{array}{l}\text { Harris Hip } \\
\text { score }\end{array}$ & $\begin{array}{l}\text { Diabetes } \\
\text { mellitus }\end{array}$ & $\begin{array}{l}\text { Osteoporosis } \\
\text { treatment }\end{array}$ & $\begin{array}{l}\text { Additional } \\
\text { fractures }\end{array}$ & Comorbidities & Malignity & Exitus \\
\hline 99 & $81.23 \pm 8.34$ & $36 / 63$ & $53.62 \pm 12.71$ & $18(18.2 \%)$ & $17(17.2 \%)$ & $12(12.1 \%)$ & $21(21.2 \%)$ & $4(4.1 \%)$ & $22(22.2 \%)$ \\
\hline
\end{tabular}

\begin{tabular}{|l|l|l|l|}
\hline Table 2. The comparison of select parameters between alive and exitus patients & p value \\
\hline $\mathrm{n}$ & Alive & Exitus & - \\
\hline Age & 77 & 22 & 0.439 \\
\hline Harris Hip score & $80.9 \pm 8.3$ & $82.4 \pm 8.7$ & 0.0001 \\
\hline Gender (F/M) & $59(\mathrm{IQR}=6)$ & $40(\mathrm{IQR}=13)$ & 0.624 \\
\hline Diabetes (+/-) & $27 / 50$ & $9 / 13$ & 0.347 \\
\hline Additional fractures (+/-) & $16 / 61$ & $2 / 20$ & 0.726 \\
\hline Osteoporosis treatment & $9 / 68$ & $3 / 19$ & 0.011 \\
\hline Comorbidities & $17 / 60$ & $0 / 22$ & 0.554 \\
\hline $\begin{array}{l}\text { Chi-square test or Fisher exact test statistic was used to compare the categorical variables. We decided whether the data should be parametric or non-parametric based on the } \\
\text { results of Kolmogorov-Smirnov or Shapiro-Wilk tests and histogram distributions. M: Male, F: Female, IQR: Interquartile range }\end{array}$ \\
\hline
\end{tabular}

\begin{tabular}{|c|c|c|c|}
\hline Additional fractures & Present & Not present & $p$ value \\
\hline Age & $81.5 \pm 8.5$ & $81.2 \pm 8.4$ & 0.906 \\
\hline Gender (M/F) & $1 / 11$ & $35 / 52$ & 0.051 \\
\hline Diabetes $(+/-)$ & $3 / 9$ & $15 / 72$ & 0.453 \\
\hline Osteoporosis treatment $(+/-)$ & $2 / 10$ & $15 / 72$ & 1.00 \\
\hline Harris Hip score & $51(\mathrm{IQR}=13)$ & $56(\mathrm{IQR}=16)$ & 0.607 \\
\hline Comorbidities (+/-) & $3 / 9$ & $18 / 6$ & 0.714 \\
\hline \multicolumn{4}{|c|}{$\begin{array}{l}\text { Chi-square test or Fisher exact test statistic was used to compare the categorical } \\
\text { variables. We decided whether the data should be parametric or non-parametric } \\
\text { based on the Kolmogorov-Smirnov or Shapiro-Wilk tests and histogram } \\
\text { distributions. M: Male, F: Female, IQR: Interquartile range }\end{array}$} \\
\hline
\end{tabular}

(6). Studies related to femoral neck fractures and epidemiology are limited and variable in our country (7-9). Literature on the investigation of the distribution of fracture types according to age has revealed that femoral neck fractures occur more frequently in elder patients than trochanteric fractures. Kannus et al. (10) stated that the mean age of male and female hip fracture patients was 69 and 78.9 years, respectively, in a large case series. In our study, since only femoral neck fractures were studied, the age distribution were found to be relatively greater when compared to that in studies inspecting the overall hip fractures.

Gender is another risk factor cited by the literature. The ratio of hip fractures for women has been reported as $68.3-74 \%(7,10)$. In our study, the mean ratio of male and female patients was similar to that suggested by the literature. In a study conducted in 2019 in England, 18 malignities were identified among 119 femoral neck fractures; however, no significant difference was recorded between the malignity and cost (11). Only 4 patients had malignity, and no cost-effectiveness analysis was conducted in our study. Overlooking the risk of malignity has a deleterious effect on the cost analysis as well as on the resultant malpractice in our country. In a prospective cohort study of 32,089 patients, Nicodemus et al. (12) specified that diabetes can lead to osteoporosis, which increases the risk of hip fractures. In past studies inspecting the relationship between diabetes and osteoporosis, unlike for type 1 diabetes, type 2 diabetes has been reported to have no association with osteoporosis $(12,13)$. Although diabetes has no significant increasing effect on osteoporosis, the comparison of bone mineral density and preoperative osteoporosis was not examined in the present study. The mortality rate of patients who underwent hip surgery ranged from 3.2\% to 35.8\% throughout the literature. However, in most of the studies, the rate of mortality was higher when compared to that in the following years (14-16). Similar to that reported in the literature, the mortality rate in our study was $22.2 \%$. In several studies, significant relationships have been defined in relation to the male gender and the presence and number of additional diseases $(14,15)$. However, in our study, no significant relationship was noted among mortality, additional diseases, age, gender, and diabetes. In several studies, postoperative hip-scoring systems were found to have high predictability on the life expectancy $(7,8,14,16)$. Similar to that in the literature, patients with high Harris Hip scores posed a low risk of mortality in our study. In this study, for patients receiving regular osteoporosis treatment, the mortality ratio 
was significantly lower when compared to those not receiving regular treatment.

\section{CONCLUSION}

The most critical factors for patients to receive surgery in relation with femoral neck fracture include the high Harris Hip score, regular osteoporosis treatment, and the lack of additional fractures affecting the survival rate. In addition, one of the most important benefits of epidemiological evaluation of the femoral neck fractures is to take the necessary precautions to minimize mortality and morbidity due to fractures.

\section{Ethics}

Ethics Committee Approval: Baskent University Faculty of Medicine Human Research Ethics Committee (K/A 19-408).

Informed Consent: Informed consent for their participation in this study was obtained from all patients.

Peer-review: Externally and internally peer-reviewed.

Financial Disclosure: Providing personnel, environmental and financial support and tools and instruments that are vital for the responsibility Baskent University.

\section{REFERENCES}

1. Lundin H, Saaf M, Strender LE, Nyren S, Johansson SE, Salminen H. One-leg standing time and hip-fracture prediction. Osteoporos Int 2014;25:1305-11.

2. Tosounidis $\mathrm{TH}$, Sheikh H, Stone MH, Giannoudis PV. Pain relief management following proximal femoral fractures: Options, issues and controversies. Injury 2015;46 (Suppl 5):S52-8.

3. Roberts KC, Brox WT. AAOS Clinical Practice Guideline: Management of Hip Fractures in the Elderly. J Am Acad Orthop Surg 2015;23:138-40.

4. Soderman $P$, Malchau $\mathrm{H}$. Is the Harris hip score system useful to study the outcome of total hip replacement? Clin Orthop Relat Res 2001:18997.
5. Roche JJ, Wenn RT, Sahota O, Moran CG. Effect of comorbidities and postoperative complications on mortality after hip fracture in elderly people: prospective observational cohort study. BMJ 2005;331:1374.

6. Ghafoori S, Keshtkar A, Khashayar P, Ebrahimi M, Ramezani M, Mohammadi Z, et al. The risk of osteoporotic fractures and its associating risk factors according to the FRAX model in the Iranian patients: a follow-up cohort. J Diabetes Metab Disord 2014;13:93.

7. Okkaoğlu MC, Özdemir M, Șeșen H, Tașkesen A, Demirkale I, Altay M. Retrospective Analysis of Epidemiological Characteristics of Elderly Hip Fractures. AATD 2016;1:17-23.

8. Ozturk I, Toker S, Erturer E, Aksoy B, Seckin F. Analysis of risk factors affecting mortality in elderly patients (aged over 65 years) operated on for hip fractures. Acta Orthop Traumatol Turc 2008;42:16-21.

9. Ugurlu M, Yılmaz S, Deveci A, Ünlü S, Tunç B, Üstü B, et al. The epidemiologic characteristics of patients that underwent surgery for hip fracture Turk J Med Sci 2012;42:299-305.

10. Kannus P, Parkkari J, Sievanen H, Heinonen A, Vuori I, Jarvinen M. Epidemiology of hip fractures. Bone 1996;18(Suppl 1):57S-63.

11. Karuppiah SV, Fillery A, Marson B. Neck of femur fracture: Previous history of malignancy is not an indication to send femoral head for routine histology. Eur J Orthop Surg Traumatol 2019;29:1231-4.

12. Nicodemus KK, Folsom AR, lowa Women's Health S. Type 1 and type 2 diabetes and incident hip fractures in postmenopausal women. Diabetes Care 2001;24:1192-7.

13. Leidig-Bruckner G, Grobholz S, Bruckner T, Scheidt-Nave C, Nawroth P, Schneider JG. Prevalence and determinants of osteoporosis in patients with type 1 and type 2 diabetes mellitus. BMC Endocr Disord 2014;14:33.

14. Aharonoff GB, Koval KJ, Skovron ML, Zuckerman JD. Hip fractures in the elderly: predictors of one year mortality. J Orthop Trauma 1997;11: 162-5.

15. Gronskag AB, Forsmo S, Romundstad P, Langhammer A, Schei B. Incidence and seasonal variation in hip fracture incidence among elderly women in Norway. The HUNT Study. Bone 2010;46:1294-8.

16. Kesmezacar H, Ayhan E, Unlu MC, Seker A, Karaca S. Predictors of mortality in elderly patients with an intertrochanteric or a femoral neck fracture. J Trauma 2010;68:153-8. 